\title{
A graphical tool to evaluate temporal coverage of occupational history by exposure measurements
}

Jelle Vlaanderen, Wouter Fransman, Brian Miller, et al.

Occup Environ Med 2010 67: 636-638

doi: 10.1136/oem.2009.053421

Updated information and services can be found at:

http://oem.bmj.com/content/67/9/636.full.html

These include:

References This article cites 13 articles, 8 of which can be accessed free at: http://oem.bmj.com/content/67/9/636.full.html\#ref-list-1

Email alerting Receive free email alerts when new articles cite this article. Sign up in the service box at the top right corner of the online article.

Notes

To order reprints of this article go to:

http://oem.bmj.com/cgi/reprintform

To subscribe to Occupational and Environmental Medicine go to:

http://oem.bmj.com/subscriptions 


\title{
A graphical tool to evaluate temporal coverage of occupational history by exposure measurements
}

\author{
Jelle Vlaanderen, ${ }^{1}$ Wouter Fransman, ${ }^{2}$ Brian Miller ${ }^{3}$ Igor Burstyn, ${ }^{4}$ Dick Heederik, ${ }^{1}$ \\ Fintan Hurley, ${ }^{3}$ Roel Vermeulen, ${ }^{1}$ Hans Kromhout ${ }^{1}$
}

${ }^{1}$ Institute for Risk Assessment Sciences, Utrecht University, Utrecht, The Netherlands

${ }^{2}$ Business Unit Quality \& Safety, TNO Quality of Life, Zeist, The Netherlands

${ }^{3}$ Institute for Occupational Medicine, Edinburgh, UK

${ }^{4}$ Community and Occupational Medicine Program, Department of Medicine, Faculty of Medicine and Dentistry, The University of Alberta, Edmonton, Alberta, Canada

\section{Correspondence to}

Jelle Vlaanderen, Institute for Risk Assessment Sciences (IRAS), Division Environmental Epidemiology, Jenalaan 18d, PO Box 80178, 3508 TD, Utrecht, The Netherlands; j.j.vlaanderen@uu.nl

Accepted 3 May 2010

\section{ABSTRACT}

Introduction In occupational epidemiology, differences in the temporal coverage of the exposure history by available exposure measurement data may affect the uncertainty of exposure estimates. In the reporting of results of studies, greater attention should be paid to the extent to which exposure assessments require extrapolation outside the timeframe for which exposure measurements are available. We propose a simple graphical method that can be used to visualise the temporal coverage of exposure history with exposure measurements and the extent of temporal extrapolation needed.

Methods We construct a graph that displays the accumulated work history years for which exposure had to be assessed in each calendar year. Years for which exposure measurements were available are shaded. The proportion of work history years covered by exposure measurements and the proportion of work history years accrued before the first measurements are summarised. When available, the actual number of measurements available in each calendar year is shown.

Results We demonstrate the application of the graphical tool in three nested case-control studies that reported on leukaemia in relation to low-level benzene exposures in the petroleum industry. Considerable differences in temporal coverage between the studies were illustrated, which may have resulted in differences in the reliability of the retrospective exposure estimates derived for these studies.

Conclusion We introduce a graphical tool for visualising the temporal coverage by available exposure measurement data in epidemiological studies and encourage others to use similar graphs to derive and share better qualitative insights into the uncertainty in exposure assessment.

\section{INTRODUCTION}

Recently, it has become more common in occupational epidemiology to assign quantitative exposure estimates to subjects' work histories, ${ }^{1}$ which allows for the elaboration of quantitative exposure-response associations. However, it is well known that errors in assigning exposures can have a large impact, in terms of bias and precision, on reported exposure-response associations. ${ }^{2-4}$

The intensity of exposure that a worker experiences on any working day depends on many factors, and is subject to considerable variability. Ideally, assessment of exposure history would be based on a set of repeated exposure measurements for all study subjects (here: workers) and for all relevant time periods in each subject's work

\section{What this paper adds}

- Differences in temporal coverage of the exposure history by available exposure measurement data may affect the uncertainty of exposure estimates derived in occupational epidemiology.

- In the comparison of epidemiological risk estimates between studies, these differences generally remain unnoticed.

- We propose a simple graphical tool that can be used to visualise the temporal coverage of exposure history by exposure measurements in occupational studies.

history. ${ }^{2}$ However, due to the high costs of exposure measurements and the fact that most occupational studies are performed retrospectively, this is rarely the case. In fact, it is common in occupational epidemiology that reliable exposure measurements are available for only a subset of workers or work locations, and for selected periods of time. Therefore, most exposure assessment methods rely on extrapolation, either through statistical models or using subjective judgements.

Much has been written about the effect of between- and within-worker variation in exposure intensity measurements, and on the attenuation bias this can induce in exposure-response relationships. ${ }^{3}$ Less attention has been paid to temporal extrapolation, such as may be necessary in studies where cumulative exposure is important, and the exposure history of the study population started years before the measurements were made. Temporal trends in exposure levels have been identified where data are available, ${ }^{5}$ but are obviously hard to infer reliably in the absence of exposure measurements. One could reasonably assume that the overall uncertainty in exposure assessment will be greatest where the degree of temporal extrapolation is greatest. Currently, publications that report results in occupational epidemiology using quantitative data provide at best limited insight into the temporal coverage of the exposure history by measurements. This hampers the evaluation of the uncertainty introduced in exposure estimation and subsequent exposure-response estimates, and makes comparisons of reliability between studies and appropriate weighting of pooled-/meta-analyses difficult. ${ }^{6}$

During a review ${ }^{7} 8$ of the data quality and consistency in three studies of leukaemia and benzene exposure in the petroleum industries from 
Canada, ${ }^{9} 10$ the United Kingdom ${ }^{11} 12$ and Australia, ${ }^{13} 14$ we devised a graphical tool to provide an insight into the temporal coverage of the exposure history by measurements. We have since developed this tool further, and illustrate its use here with data from the three studies.

\section{METHODS: A GRAPHICAL SUMMARY}

Whether obtained from employment records or by interview, a subject's work history will typically contain start and finish dates of employment (sometimes in individual jobs throughout the subject's career within a company). From these, years (or months) of work history can be logged against calendar years (or months). 'Work history years' can be thus defined as the years of a subject's tenure for which exposure has to be assessed. We cumulate these across study subjects to give a total number of 'work history years' in each calendar year. These can be plotted against calendar year in the form of a bar graph, in which the height of each bar represents the total number of work history years in a given calendar year.

If we know for which years exposure measurements are available, we can distinguish these years on our graph by shading, as in the upper part of figure 1. We can summarise numerical aspects of the pattern this produces in a number of ways, such as the proportion of work history years covered by exposure measurements and the proportion of work history years accrued before any measurements were taken. The latter is an indicator of how much extrapolation outside the observational data needs to be done to estimate past exposure levels.

As an aid to interpretation, we can add to the graph a representation of the actual number of measurements available in each year. The lower part of figure 1 shows one way that this can be done, with the measurement numbers plotted, again as year-specific bars, below the horizontal axis. In some cases, the exact numbers of measurements taken in each year may not be available, but we can adopt a convention to show this: here we have drawn a line around the bar where the figure is for a particular year, but omitted the border where the distribution over a block of years is unknown, and the height of the block represents the average number per year.

\section{AN EXAMPLE: THREE STUDIES OF BENZENE AND LEUKAEMIA}

As part of a comparative review, ${ }^{78}$ we devised an early version of the graphs presented here to compare the exposure assessments in three nested case-control studies on leukaemia in relation to low-level benzene exposures in the petroleum industry. ${ }^{10} 1214$ The methods of exposure assessment developed for the Canadian study ${ }^{9}$ were adopted by the other two studies working in collaboration, ${ }^{11}{ }^{13}$ so the exposure assessment and assignment methods were, in principle, comparable. The review of the three studies ${ }^{78}$ noted that the time periods for which exposure had to be assessed were similar for the studies in Canada (1909-1983) and the UK (1909-1993), but in the Australian study the period to be covered was more recent (1941-1998) and needed less extrapolation backward. The information regarding coverage of the work history years by exposure measurements, as supplied by the principal investigators of the three studies, is summarised in figure 1. Note that these descriptions do not distinguish between jobs within the industry. As seen from the graph, although the total number of work history years in the UK and Australia were similar, in Australia they were distributed over a more recent period. The Canadian graph is much shallower, reflecting the smaller number of total work history years. For the UK study, only temporal coverage of work history years with exposure measurements was provided, and no information was available
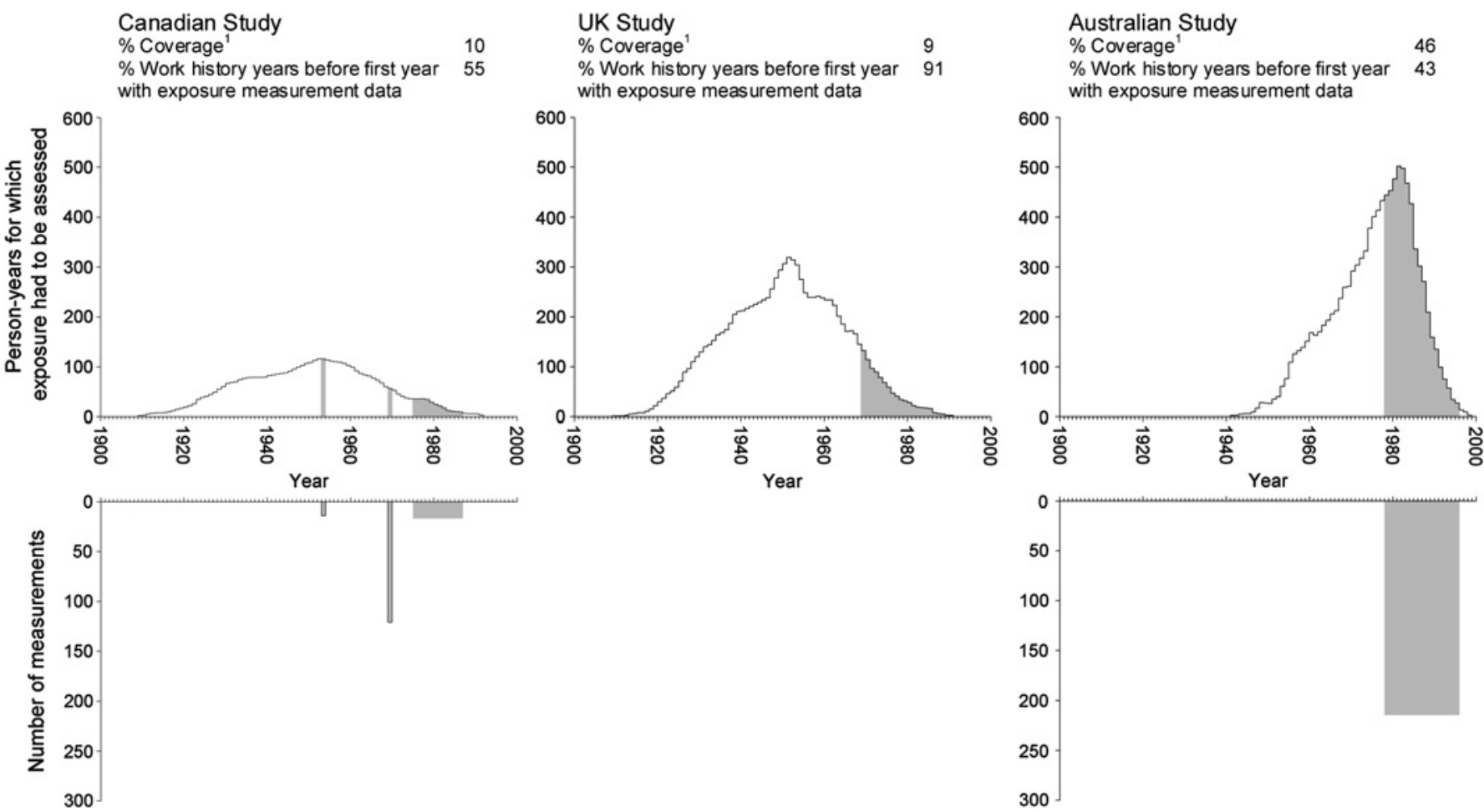

Figure 1 The upper plot is a graphical representation of the temporal distribution of the accumulated work history years in a study. Calendar years for which exposure measurements are available are hatched. The total number of work history years available for each study was 4557 (Canadian study), 10258 (UK study) and 10922 (Australian study). The lower plot is a bar graph of the number of available exposure measurements per calendar year. The Canadian study used 340 exposure measurements, and the Australian study used more than 3870 measurements. The number of measurements used in the UK study is unknown. 'Coverage of work history years by available exposure measurement data. 
on the number of measurements used for exposure assessment, either by year or in total. The temporal coverage of total work history by exposure measurements was larger for the Australian study (46\%) than for the Canadian (10\%) and UK (9\%) studies. The proportion of work history years before the first year with exposure measurements ranged from $91 \%$ in the UK study to $55 \%$ in the Canadian study and $43 \%$ in the Australian study. The figure for Canada would be very much higher (87\%) without the small proportion of measurements $(n=14,4 \%)$ taken in 1953, many years before the other measurements. Given the similarities between studies in methods for exposure assessment and assignment, these results suggest that the uncertainty in exposure assessment in the Canadian and UK studies was larger than in the Australian study.

\section{DISCUSSION}

Although differences in the temporal coverage of the exposure history by available exposure measurement data may affect the degree of uncertainty in quantitative exposure estimates that are used in occupational epidemiology, they generally remain unnoticed in the evaluation of epidemiological results. We believe they should be given greater prominence, and have developed a tool that visualises coverage of exposure history by measurements. Our method can be readily adapted to any situation where temporal coverage of work history by measurements is important, for example at the level of jobs within a particular industry or workplace.

The numerical summary measures we show conceal complexity that may be relevant to uncertainty analysis. For several periods in our example, only the cumulative number of exposure measurements during a certain period was known, and we were not able to assess the exact number of measurements per calendar year. Therefore, we graphed the annual average. The summary value of the proportion of work history years before any measurements is rather sensitive to the appearance of isolated early measurements, as was demonstrated in the Canadian data. Another option would be to count coverage only for years in which a specified minimum number of measurements was available. The graphical tool should be seen as an addition to the evaluation of other factors that may affect the degree of uncertainty in quantitative exposure estimates that are used in occupational epidemiology, such as the precision and accuracy of the assessment of the within- and between-worker variation in exposure intensity. ${ }^{3}$

\section{CONCLUSION}

We present a simple tool that can assist in reporting the extent to which exposure assessment relies on extrapolation outside the time frame for which measurements of exposure are available. Various adaptations of the tool we introduce could be developed and we offer it here in the hope of stimulating such reporting.

Acknowledgements The authors are indebted to the principal investigators who supplied data for use in the comparative review of their studies of low-level benzene exposure and leukaemia.

Funding The comparative review of the three nested case-control studies was funded by CONCAWE (Boulevard du Souverain 165, B-1160, Brussels, Belgium). Development of the methods described here was partly supported by ECNIS (European Cancer Risk, Nutrition and Individual Susceptibility), a Network of Excellence operating within the European Union 6th Framework Program, Priority 5: 'Food Quality and Safety' (Contract No 513943). Igor Burstyn was supported by the Population Health Investigator salary award from the Alberta Heritage Foundation for Medical Research

Competing interests None.

Provenance and peer review Not commissioned; externally peer reviewed.

\section{REFERENCES}

1. Kriebel D, Checkoway H, Pearce N. Exposure and dose modelling in occupational epidemiology. Occup Environ Med 2007;64:492-8.

2. Heederik D, Attfield M. Characterization of dust exposure for the study of chronic occupational lung disease: a comparison of different exposure assessment strategies. Am J Epidemiol 2000;151:982-90.

3. Loomis D, Kromhout $\mathrm{H}$. Exposure variability: concepts and applications in occupational epidemiology. Am J Ind Med 2004;45:113-22.

4. Tielemans E, Kupper LL, Kromhout H, et al. Individual-based and group-based occupational exposure assessment: some equations to evaluate different strategies. Ann Occup Hyg 1998;42:115-19.

5. Kromhout $\mathbf{H}$, Vermeulen R. Long-term trends in occupational exposure: are they real? What causes them? What shall we do with them? Ann Occup Hyg 2000;44:325-7.

6. Vlaanderen J, Vermeulen R, Heederik D, et al. Guidelines to evaluate human observational studies for quantitative risk assessment. Environ Health Perspect 2008;116:1700-5.

7. Miller BG, Fransman W, Heederik D, et al. A review of the data quality and comparability of case-control studies of low-level exposure to benzene in the petroleum industry. Int Arch Occup Environ Health 2010;831:69-76.

8. Miller BG, Fransman W, Heederik D, et al. A review of the data quality and comparability of case-control studies of low-level exposure to benzene in the petroleum industry (IOM Report TM/05/04). Edinburgh: Institute of Occupational Medicine, 2005. http://www.iom-world.org/pubs/IOM_TM0504.pdf.

9. Armstrong TW, Pearlman ED, Schnatter AR, et al. Retrospective benzene and total hydrocarbon exposure assessment for a petroleum marketing and distribution worker epidemiology study. Am Ind Hyg Assoc J 1996;57:333-43.

10. Schnatter AR, Armstrong TW, Nicolich MJ, et al. Lymphohaematopoietic malignancies and quantitative estimates of exposure to benzene in Canadian petroleum distribution workers. Occup Environ Med 1996;53:773-81.

11. Lewis SJ, Bell GM, Cordingley N, et al. Retrospective estimation of exposure to benzene in a leukaemia case-control study of petroleum marketing and distribution workers in the United Kingdom. Occup Environ Med 1997;54:167-75.

12. Rushton L, Romaniuk H. A case-control study to investigate the risk of leukaemia associated with exposure to benzene in petroleum marketing and distribution workers in the United Kingdom. Occup Environ Med 1997;54:152-66.

13. Glass DC, Adams GG, Manuell RW, et al. Retrospective exposure assessment for benzene in the Australian petroleum industry. Ann Occup Hyg 2000;44:301-20

14. Glass DC, Gray CN, Jolley DJ, et al. Leukemia risk associated with low-level benzene exposure. Epidemiology 2003;14:569-77. 